\title{
Hemodynamic monitoring for Fetal Surgery: Open versus Fetoscopic Repair of Myelomeningocele
}

\author{
Ayten Saraçoğlu', Kemal Tolga Saraçoğlu', Hüseyin Canaz², İbrahim Alataş², \\ Ali Gedikbaşı ${ }^{3}$, i. Haluk Kafalı'
}

\author{
Department of Anesthesiology and Intensive Care', Neurosurgery ${ }^{2}$, Obstetrics and Gynecology, \\ Istanbul Bilim University Medical School, Turkey
}

\begin{abstract}
Background and goals:
Myelomeningocele (MMC), a severe form of spina bifida, is characterized by protrusion of the meninges and spinal cord through a defect in the vertebral column.' MMC occurs in approximately $I$ in 3,000 live births in the United States.

2 Procedure-associated maternal and fetal risks were determined for both open and fetoscopic repair of MMC.

However to date, there has been no comparison of intraoperative hemodynamic management.

We have recently published the results of the conformational analysis of perioperative data during fetoscopic surgery. ${ }^{3}$ In this case series we aimed to evaluate the stability of hemodynamic parameters and blood gas values during open fetal surgery.

Methods:

Following the patients' written informed consents we analysed the data of 4 patients undergoing open fetal surgery for myelomeningocele at 26 weeks' gestation. The mean age was $33.3 \pm 4.3$ years. The $\mathrm{PICCO}_{2}$ was used for the hemodynamic monitoring. We analysed the data before surgery, during surgery at I $^{\text {st }}$ hour and immediately after surgical procedure.

Fetal cardiac activity was monitored during fetal surgery to assess fetal viability and well-being, and intermittent fetal umbilical blood flow was measured. Afterwards, peak systolic (PS) and end-diastolic (ED) umbilical blood flow patterns were recorded during anesthesia induction $\left(T_{1}\right)$, fetal meningocele repair $\left(T_{2}\right)$ and after the uterus was closed $\left(\mathbf{T}_{3}\right)$.

Table I: The hemodynamic variables during the perioperative period
\end{abstract}

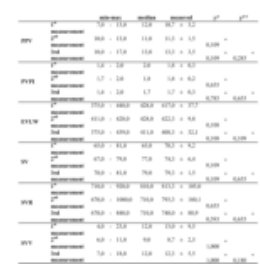

Table 2: The umblical flows obtained from patients:

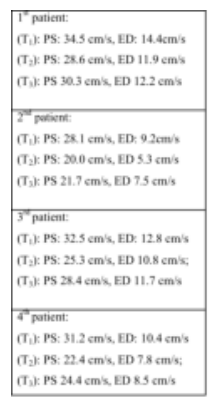

\section{Results:}

Preoperative and postoperative hemodynamic data of patients showed no significant difference (Table I). During anesthesia and surgery, umbilical blood flows, especially diastolic flow may decelerate. These changes were reversible, and returned to normal after surgery (Table 2). There was no complication. In both open and fetoscopic procedures, the umbilical blood flows and the hemodynamic parameters didnot change significantly. Both methods have been demonstrated to improve the pediatric outcomes. However there are several limitations to compare the techniques.

Small sample size is one major factor to estimate the longterm neurodevelopmental outcomes. Joyeux et al. ${ }^{4}$ compared the results of published papers on fetoscopic $(n=5 I)$ and open approach $(n=71)$. Perinatal mortality and shunt rate at 12 months were similar. In our series hydrocephalus and chiari type II malformation improved later in all cases and non of the patients needed ventriculoperitoneal shunt after birth. On the other hand fetoscopic surgery took longer operation time (223 vs. $105 \mathrm{~min}, \mathrm{p}<0.001)$, had higher postnatal reoperation ( $28 \%$ vs $2.56 \%, p<0.00 I)$ and preterm prelabor membrane rupture rate $(84 \%$ vs $46 \%, p<0.00 I)$ with an earlier gestational age at birth ( 32.9 vs 34.1 weeks, $p=0.03)$. In our comparison the mean duration time for fetoscopic and open approach were $\mathbf{2 5 5}$ minutes and 130 minutes respectively $(p<0.05)$. Besides Pulse Pressure Variation Pulmonary Vascular Permeability Index, extravascular lung water or Stroke volume were valuable parameters for us to evaluate the fetal well being. We supported our results with the umbilical cord flow rates. Therefore by $\mathrm{PICCO}_{2}$ monitoring and Doppler ultrasound, goal directed anesthetic and surgica management provided optimal maintenance of fetal and maternal well-being.

Conclusion:

In conclusion although there are technical differences between minimal invasive and open procedures both methods have similar effects in hemodynamic monitoring parameters and umblical cord flow.

References:

I. Kabagambe SK, Jensen GW, Chen YJ, et al. Fetal Surgery for
Myelomeningocele: A Systematic Review and Meta-Analysis of Outcomes in Fetoscopic versus Open Repair. Fetal Diagn Ther 2017 Sep I5. [Epub ahead of

print]

2. Committee on Obstetric Practice, Society for Maternal-Fetal Medicine.

Committee Opinion No.nn 720: Maternal-Fetal Surgery for Myelomeningocele. Obstet Gynecol 2017; 1 30:e 164-el67.

3. Saracoglu A, Saracoglu KT, Kafali IH. The importance of maintaining an optimal hemodynamic state during minimally invasive fetal surgery. J Clin Anesth 2016;34:365-6.

4. Joyeux L, Engels AC, Russo FM, et al.

Fetoscopic versus Open Repair for Spina Bifida Aperta:

A Systematic Review of Outcomes. Fetal Diagn Ther 2016;39:16I-7I. 